NBER WORKING PAPER SERIES

\title{
ORGANIZATIONAL ECONOMICS AND PHYSICIAN PRACTICES
}

\author{
James B. Rebitzer \\ Mark E. Votruba \\ Working Paper 17535 \\ http://www.nber.org/papers/w17535
}

\author{
NATIONAL BUREAU OF ECONOMIC RESEARCH \\ 1050 Massachusetts Avenue \\ Cambridge, MA 02138 \\ October 2011
}

In writing this essay, we benefited from suggestions provided by Lawton R. Burns, Alan B. Cohen, Keith Ericson, Meredith B. Rosenthal, Mark Rukavina and Victor Fuchs. We are responsible for any errors or omissions. The views expressed herein are those of the authors and do not necessarily reflect the views of the National Bureau of Economic Research.

NBER working papers are circulated for discussion and comment purposes. They have not been peerreviewed or been subject to the review by the NBER Board of Directors that accompanies official NBER publications.

(C) 2011 by James B. Rebitzer and Mark E. Votruba. All rights reserved. Short sections of text, not to exceed two paragraphs, may be quoted without explicit permission provided that full credit, including (C) notice, is given to the source. 
Organizational Economics and Physician Practices

James B. Rebitzer and Mark E. Votruba

NBER Working Paper No. 17535

October 2011, Revised June 2013

JEL No. D02,D23,I11,I12,J4,J44,M5

\begin{abstract}
$\underline{\text { ABSTRACT }}$
Economists seeking to improve the efficiency of health care delivery frequently emphasize two issues: the fragmented structure of physician practices and poorly designed physician incentives. This paper analyzes these issues from the perspective of organizational economics. We begin with a brief overview of the structure of physician practices and observe that the long anticipated triumph of integrated care delivery has largely gone unrealized. We then analyze the special problems that fragmentation poses for the design of physician incentives. Organizational economics suggests some promising incentive strategies for this setting, but implementing these strategies is complicated by norms of autonomy in the medical profession and by other factors that inhibit effective integration between hospitals and physicians. Compounding these problems are patterns of medical specialization that complicate coordination among physicians. We conclude by considering the policy implications of our analysis - paying particular attention to proposed Accountable Care Organizations.
\end{abstract}

James B. Rebitzer

Professor of Management, Economics, Public Policy

Markets, Public Policy and Law Department

Boston University School of Management

595 Commonwealth Ave.

Boston, MA 02215

and NBER

rebitzer@bu.edu

Mark E. Votruba

Weatherhead School of Management

Case Western Reserve University

11119 Bellflower Road

Cleveland, OH 44106

mark.votruba@case.edu 


\section{Introduction}

It is a commonplace to observe that the health care delivery system in the U.S. is in crisis: costs are high and rising rapidly; the quality of care is inadequate along important dimensions; and the delivery system is rife with inefficiencies and waste (Baicker and Chandra 2011). What is less commonly acknowledged is that many of the prominent strategies for reforming the delivery system are based on strong, largely untested beliefs about how organizations can best coordinate and motivate the physicians involved in patient care.

Health services researchers have long argued that a central problem with health care delivery in the US is fragmentation (Cebul et al. 2008). Individual patients are frequently treated by numerous care providers who have only weak organizational ties with one another, resulting in poor information flows and inadequate care coordination. This fragmentation especially inhibits the close coordination between diverse providers that is required to manage costly chronic diseases and to prevent errors and missteps. The obvious fix, according to this view, is to induce physicians to join or construct more integrated care delivery systems. As a step in this direction, the Patient Protection Affordable Care Act of 2010 directs the Centers for Medicare and Medicaid Services to create a voluntary program for Accountable Care Organizations (ACOs). This program is designed to nudge the US health care system towards more integrated care delivery (Shortell, Casalino and Fisher 2010)

In contrast to the health services research community, many economists have argued that the fundamental problem with the delivery system is poor incentives, primarily physician incentives (McClellan 2011). From this perspective, the continuing dominance of fee-for-service payment systems and flawed payment rates within these systems create strong incentives for physicians to deliver high-cost services. ${ }^{1}$ Incentives to improve care quality are largely indirect and weak - patients presumably seek out higher quality physicians but have little ability to evaluate physician quality. Expensive and inefficient

\footnotetext{
${ }^{1}$ Fee for service doesn't by itself necessarily lead to oversupply, rather it leads to oversupply for services whose fees exceed marginal costs as may have happened in the United States for coronary artery bypass graft (CABG) under Medicare's prospective pay system (Kim 2011)
} 
practice styles are further supported by overly generous insurance coverage, a consequence of tax breaks for employer-based coverage and the widespread use of supplemental Medicare coverage. ${ }^{2}$

The result is a bloated system where neither physicians nor patients are held directly accountable for the financial consequences of their care decisions. The obvious fix, according to this view, is to get incentives right by reforming payment systems and tax policy (President's Council of Economic Advisors 2004). Thus ACOs are encouraged to adopt new payment systems that, in principal, reward physicians for adopting practice styles that reduce costs and improve quality. ${ }^{3}$ At the heart of these payment reform proposals is an economic theory of how best to motivate physicians using material incentives.

In this paper, we present an overview of organizational economics as it applies to physician practices. We begin in section one with a brief descriptive overview of the structure of physician practices. Our point will be that the long anticipated triumph of integrated care delivery has largely gone unrealized. While fewer physicians are working in solo practices than in the past, self-employed physicians in small group practices remain the industry norm. Integration of physicians' business functions has increased through a variety of cross-group and group-hospital affiliations, but integration of clinical activities has lagged. In section two we discuss the problem of pay for performance from the perspective of the economic theory of principal agent models. Building on these models, sections three and four take up the organizational economics of integrated care. Section three examines the professional norms of autonomy and other factors that complicate effective integration between hospitals and physicians; and section four considers how medical specialization affects coordination across providers. In section 5, we consider how the problems of motivation and coordination play out in ACOs.

\footnotetext{
${ }^{2}$ Even with less generous insurance, price competition would arguably remain weak as consumers (currently) have little ability to compare provider prices (Ginsburg 2007) and because prices in the Medicare market are administratively determined.

${ }^{3}$ The new payment models for ACOs have a variety of labels: "episode payments", "comprehensive care payments", and "comprehensive care global payments". Other proposals for reforming payments to increase incentives for cost-conscious medicine involve combining high deductible insurance plans with tax advantaged health savings account. These last proposals shift incentives onto patients rather than physicians and so lie beyond the scope of this paper.
} 


\section{A Descriptive Overview}

The physician workforce has evolved over time in both size and composition. In the mid- $20^{\text {th }}$ century, there were approximately 14 physicians per 10,000 persons in the United States, almost half of whom practiced general primary care (see Table 1). In response to concerns about an impending physician shortage, the Kennedy and Johnson administrations successfully championed legislation subsidizing medical schools ( Blumenthal 2004 ; Ludmerer 1999; Starr 1984), doubling the number of medical school graduates from 1965 to 1980, and eventually doubling the physician-to-population ratio from 1970 to 2000. Despite a subsequent stabilization of medical school graduation rates, entry into the medical profession continued to modestly outpace population growth largely through an increase in international medical graduates, who now comprise a quarter of active physicians.

As medical knowledge and technology grew, the share of general practitioners in the medical profession declined more than 60 percent between 1949 and 1970, at which time fewer than 20 percent of active physicians practiced general primary care. The share of general practitioners continued its steep decline through the 1980s, though the decline was partially offset by growing shares of physicians practicing in specialties that typically involve primary care services, i.e. pediatrics, obstetrics/gynecology and internal medicine. Since 1990, the share of primary care physicians (general practitioners plus primary care specialties) has largely stabilized at 39 percent of all active physicians. While the physicianpopulation ratio in the U.S. is similar to that in other developed countries, its share of primary care physicians is substantially lower and this has been cited by numerous health policy experts as an important deficiency in the U.S. health care delivery system (see, e.g., Starfield, Shi and Macinko 2005).

The trend towards an increasing concentration of medical specialists has been accompanied by an increasing "feminization" of the physician workforce and, more recently, by a decline in the labor supply of individual physicians. Historically, the medical profession was overwhelmingly dominated by male physicians. In 1970 about 7 percent of active physicians were women but the share of female physicians has grown consistently since then, reaching 31 percent by 2008. Coinciding with this change has been a decline in the number of hours physicians work each week, especially since the mid-1990s (Staiger, 
Aurebach and Buerhaus 2010). Thus, while active physicians per capita increased 17 percent since 1990, physician work hours per capita increased less than 7 percent. $^{4}$

Table 2 documents trends in care delivery settings. Chief among these is a dramatic decrease in the amount of inpatient care provided. Since 1975, hospital admission rates have declined roughly 25 percent, while the length of hospital stays fell by almost one-half, representing a substantial decline in the amount of care physicians provide on an inpatient basis. In contrast, hospital-based outpatient care increased dramatically over this time, driven in part by a steep rise in outpatient surgeries. ${ }^{5}$ Meanwhile, the per capita rate of office-based visits increased 17 percent since 1975, but this aggregate figure combines two very different trends. The rate of primary care visits was relatively flat over this period, consistent with relative stability in the (per capita) number of primary care physicians, while per capita office-based visits to specialists increased by more than 50 percent.

Thus a two-fold story emerges from Table 2. First, physicians spend less time "making rounds" and performing procedures in an inpatient setting than they did in the past, decreasing the dependence of physicians on hospitals as the setting for delivering services. Second, the decrease in inpatient care has coincided with a dramatic increase in ambulatory care delivered by medical specialists.

In Tables 3 and 4, we document how physician employment and practice arrangements have evolved over time. The results in Table 3 report statistics derived from a series of physician surveys conducted by the American Medical Association - the Periodic Survey of Physicians (1975), the Socioeconomic Monitoring Study (1983-1999), and the Patient Care Physician Survey (2001) - through 2001. ${ }^{6}$ More recent trends are documented in Table 4 drawing on data collected by the Center for Studying Health Systems Change (HSC) - four waves of data from the Community Tracking Study

\footnotetext{
${ }^{4}$ This, combined with the increasing health care demands of an aging population, has contributed to concerns regarding an impending physician shortage. See, e.g. Cooper et al. (2002) and Kane et al. (2009).

${ }^{5}$ Among non-federal community hospitals, the percent of surgeries conducted on an outpatient basis increased from 16.3 percent in 1980 to 62.7 percent in 2000, but has since stabilized. The rate was 63.2 percent in 2008. (Source: National Center for Health Statistics 2011.)

${ }^{6}$ The results in Table 3 rely on statistics published in AMA reports, leading to omitted measures in some years and a different categorization of "group size" after 1983.
} 
(CTS) Physician Survey and the HSC 2008 Health Tracking Physician Survey. Caution is always warranted in evaluating trends across different surveys. A special concern in this case is the sampling methodology of the CTS Physician Survey, which focused on 60 communities in the US. All statistics are weighted to be nationally representative, but trends in these communities may have differed from those in other areas, which could confound some of the cross-study patterns we observe. Nonetheless, these results allow us to draw a number of conclusions.

(1) Physician self-employment has declined, but remains the norm. ${ }^{7}$ For much of U.S. history the prototypical physician was self-employed and in solo practice. Even as recently as 1983, over 40 percent of physicians fit this model but its numbers have been declining. By 2001 under 25 percent of physicians were self-employed in solo practices. Overall rates of physician self-employment largely track the decline in solo practitioners, falling from 76 percent in 1983, to around 64 percent in 2000 (in AMA data), to under 56 percent in 2008 (HSC data). In the CTS data, self-employment rates were somewhat lower than in AMA data, but a similar modest decline in self-employment rates is observed.

(2) Institutional employment increased, but then appears to have stabilized (probably). The AMA data indicate that that the share of physicians working as employees of institutions (e.g. hospitals, medical schools, HMOs, etc.) grew from 20 to 28 percent from 1988 to 1994 - during the ascent of managed care - and then was fairly stable to 2001. The HSC data similarly find that about 28 percent of physicians were employees of institutions in 2008, suggesting little change over the last decade. The CTS data tell a somewhat conflicting story over the decade from 1996 to 2005, with rates of institutional employment seeming to increase from 31 percent to 36 percent. Given the nature of the CTS sampling methodology, we are inclined to believe this trend may not be representative of the nation as a whole, and that national rates of institutional employment have probably stabilized at a level less than 30 percent. It is likely, however, that local health care markets are quite heterogeneous in this regard.

\footnotetext{
${ }^{7}$ Following the AMA's definition, we define “self-employed” as physicians with partial or full ownership in their main practice. In the vast majority of cases, this is ownership in a (non-institutional) group practice.
} 
(3) Practice groups have gotten larger, but small practices remain the norm. Health system analysts have been predicting the demise of solo and small group practices for decades (see, e.g. Crosson 2009). Based on AMA data, it appears that a majority of non-institutional physicians were in solo practice in 1975, declining to a third by 2001. Meanwhile, the share of employment in physician groups with more than 10 physicians grew from 12 percent to 19 percent between 1988 and 2001. The CTS data indicates the share of non-institutional physicians in solo or two-physician practices declined from 59 percent in 1996-97 to 51 percent in 2004-05, while the share in groups with 6 or more physicians increased from 23 percent to 34 percent. The historic record, then, is one of decreasing shares of physicians in the very smallest practices, and increasing shares in larger groups. Despite this, however, small groups remain a common feature of the physician labor market. In 2008, 65 percent of noninstitutional physicians were in practices with 5 or fewer physicians, accounting for 46 percent of the physician workforce overall.

Practice size and the prevalence of physician institutional employment (in hospitals and staffmodel HMOs) provide an incomplete picture of the extent that individual physicians coordinate activities with one another and with other providers in the health care system. Over the last few decades, physician groups have increasingly joined a variety of cross-group and group-hospital organizations intended to facilitate the collective goals of their participants.

Independent practice associations (IPAs) have emerged to provide solo and small group practices many of the benefits associated with larger group practice - economies of scale in insurance contract negotiations, contract oversight, and other administrative functions - while allowing participating physicians greater autonomy over their individual practices. According to the Managed Care Information Center, there are currently about 500 IPAs with around 264,000 participating physicians, which equates to roughly 55 percent of the active physicians in group practice (Bazzoli et al. 2004).

A variety of organizations have emerged linking physicians and hospitals, with the goal of integrating service delivery and financing. The most common of these, known as physician hospital organizations (PHOs), represent joint ventures between hospitals and private physicians to negotiate and 
manage insurance contracts. PHOs also frequently operate clinics, employ physicians and staff, and acquire medical practices. Some have established their own insurance products. At the apex of managed care in the mid 1990s, nearly a third of hospitals had one or more PHOs. The fraction has subsequently declined, falling to 13.4 percent by 2008 (American Hospital Association 2010). Bazzoli et al. (2004) found that other sorts of physician-hospital arrangements had a similar pattern of initial increases followed by a subsequent decline.

A third type of organization, known as management service organizations (MSOs), are organizations owned by physician groups, by physician-hospital ventures, or by investors in conjunction with physicians. MSOs generally exist to provide practice management and administrative support, thus relieving practices of non-medical business functions. In some cases, MSOs acquire the facilities and equipment of their client physicians which they then lease back to the physicians. ${ }^{8}$

The widespread existence of such organizations can give the impression that physicians, even those in small practice, are often tightly aligned with one another and frequently integrated with hospitals in their geographic area. However, closer inspection suggests a more nuanced story (see Bazzoli et al. 2004 for an excellent review). The rise of cross-group and group-hospital organizations was largely due to the market pressures imposed by managed care organizations. Consolidating business functions allowed groups to achieve economies of scale in non-medical activities and, more importantly, increased the clout of providers in contract negotiations. These organizations, however, were largely unsuccessful at integrating clinical activities across participating providers. As managed care backed away from capitated contracts, the impetus to integrate clinical activities largely faded (Bazzoli et al. 2004).

\section{Agency and Pay for Performance}

Physicians know more than patients or insurers about the set of effective treatment options available for an individual with a specific condition. A patient's own physician knows better than other

\footnotetext{
${ }^{8}$ There are many variations on IPAs, PHOs and MSOs. For instance, physicians can belong to IPAs, which are in turn part of a PHO, which is itself administered with support from a MSO (Shortell et al. 1998).
} 
physicians the specifics of the patient's clinical and personal situation. Specialists, with their advanced training and narrow focus on a small set of clinical issues, have a better understanding of treatment options in their specialty than the primary care providers who refer patients to them. Each of these informational asymmetries creates an agency problem, i.e. a situation in which well-informed physicians recommend or implement courses of action that benefit the well-informed physician at the expense of patients, payers, and other less-well-informed parties.

One way to resolve information asymmetries is to design incentive contracts that motivate the best informed agent to “do the right thing”. Economics offers a well-developed theory for tackling these incentive design problems, the principal agent (PA) model. The canonical PA model considers how a principal might structure incentives to elicit optimal behavior from better informed agents whose interests do not completely conform to the interests of the principal. The principal conditions pay on observed outcomes and the actions taken by the agent reflect the influence of these incentives. The starting point for the vast literature on PA models is a remarkable and quite general result: it is possible to implement a reward structure that can elicit efficient behavior on the part of the agent even when agents are entirely self-interested and even when performance measures are noisy and imperfect (Rebitzer and Taylor 2010). ${ }^{9}$

On the basis of this fundamental result, one might expect that the economist's prescription for efficient health care delivery would be widespread use of pay for performance contracts. Unfortunately economic theory does not support such a simple policy prescription. The qualifications on the fundamental PA result are almost as far reaching as the result itself. ${ }^{10}$

\footnotetext{
${ }^{9}$ More precisely there exists a level of incentive intensity that generates first-best effort levels that principals will find profit maximizing to use. Noise in performance measures creates variation in the income the agent receives, but for risk neutral agents this income variation will not affect their decisions. Things are quite different, however, if agents are risk averse or if there are important aspects of performance or quality that are not included in performance measures. We discuss these qualifications below. For an empirical and theoretical discussion of the effect of risk-aversion on pay for performance see Gaynor and Gertler (1995).

${ }^{10}$ The PA model is quite abstract and so does not consider the many complications involved in applying pay for performance to a clinical environment. For a clear overview of different approaches to applying performance pay in health care see Rosenthal (2008).
} 
The first qualification has to do with the basic statistical properties of performance measures. Clinical outcomes are often influenced by some unknown combination of good actions (taken by the health care provider and/or the patient) and good luck. Because of the great diversity of possible medical conditions a patient can manifest and the limited number of patients in a physician's panel of patients, it is not at all clear that an individual physician’s practice offers enough observations to reliably distinguish good luck from good medical practice. For example, a recent study (Nyweide et al. 2009) finds that primary physician practices had annual median caseloads of 260 Medicare patients with 25 women eligible for mammography and 30 with diabetes. With such low numbers, individual primary care physician practices simply do not have a sufficient caseload to detect a $10 \%$ improvement in the rate of use of such sensible preventive care as hemoglobin A1c testing. If real improvements in such a simple to measure practice cannot be distinguished from changes due to random chance, rewarding process improvements comes uncomfortably close to rewarding luck. ${ }^{11}$

Noise in performance measures becomes even more important when agents are risk averse. ${ }^{12}$ To see this, consider a setting in which physicians operate under a contract that rewards them for coming in under a threshold level of costs for their entire panel of patients. If costs vary substantially in a year due to actions outside of a physician's control, then large payouts for coming in under target add a considerable component of randomness to a physician's compensation. For risk-averse physicians, the increase in the variability of payments that result from incentive pay imposes a real cost. To make matters worse for incentive design, income variability rises with the intensity of the incentive. As a practical matter, insurers or HMOs that ignore the cost of this increased risk when implementing pay for performance will find they will need to pay more to attract physicians to their networks.

\footnotetext{
${ }^{11}$ The low power of performance measures is exacerbated by the fact that care delivery is spread across a number of different providers and that the identity of the primary care provider is difficult to uncover from Medicare or from commercial insurance records. For example, Pham et al. (2007) report that in their sample of Medicare patients, the median patient saw two primary care physicians and five specialists working in four different practices.

${ }^{12}$ See Gaynor and Gertler (1995); and Encinosa, Gaynor and Rebitzer (2007) for a discussion of this point. Performance measures are also likely to be imperfect because they do not include many important dimensions of quality. We take this up when we discuss multi-tasking problems in section III.
} 
The problems posed by the low statistical power of clinical performance measures and the risk aversion of physicians can be mitigated by pooling information across many physicians. Nyweide et al. (2009) report that for practices with fewer than 11 primary care physicians, only $10 \%$ would have sufficient caseloads to detect a 10\% relative improvement in physician performance. In contrast, practices with 50 or more physicians would be able to detect a $10 \%$ relative performance improvement a $100 \%$ of the time. Averaging performance measures across doctors similarly reduces the variability of payouts from pay for performance systems.

From an economic perspective, pooling or averaging performance measures is problematic because it makes agency problems worse. The larger the physician panels across which outcomes are measured, the less will be the effect of an individual physician's actions on group outcomes. ${ }^{13}$ The phenomenon of group incentives weakening as the size of the group increases is well understood in the economics literature where it is often referred to as the "free-riding" problem. There is some evidence that free-riding matters for physician groups. Gaynor, Rebitzer and Taylor (2004) study an HMO that divided physicians into panels of doctors (or PODS) for the purpose of measuring cost containment and awarding financial rewards to physicians who kept costs under a predetermined budget cap. Consistent with free-riding, they found that PODs with three physicians were much more effective at coming in under the cap than PODs with six or more physicians.

The relevance of free-riding problems is evident when one looks at the pay practices of physicians groups. Physicians who work in group practices often share revenues among themselves. Revenue sharing has the appeal of allowing physicians to buffer variations in income (doctor A's extra income in a good year will help offset doctor B's poor income in a down year), but this insurance comes at the cost of weakening incentives. If revenues are equally shared, a doctor in a three person group keeps $1 / 3$ of each dollar she earns. Incentives weaken as the size of the group grows: a doctor in a five person

\footnotetext{
${ }^{13}$ See Frandsen and Rebitzer (2013b) for some theory and evidence on the trade-off between the statistical power of performance measures and free-riding in medical groups. It is often claimed that process improvements are generally measured with less noise than outcome measures. Some recent work for the United Kingdom indicates that improvements in process measures as a result of pay for performance incentives are positively associated with outcomes (Ryan and Doran 2012 ).
} 
group keeps $1 / 5^{\text {th }}$ of the marginal dollar in revenues they earn and so on. Encinosa, Gaynor and Rebitzer (2007) study the trade-off of insurance and incentives in medical practices and find that small groups are much more likely to adopt “equal sharing rules” than large groups. As group size grows, physicians are allowed to keep a larger share of the revenues they bring in (see also the analysis in Gaynor and Gertler 1995).

If it is costly or difficult to use incentives to resolve agency problems with meaningful pay for performance systems, organizations might find it profitable to reduce the need for incentives by seeking out physicians who have their principal's interests at heart. Consider a hypothetical physician who is committed to providing patients with the level of care the patient would choose for themselves if they knew as much as the physician knew and if the marginal cost of care were zero. Finding physicians with such "altruistic" preferences may not be as hard as it seems. Many aspects of medical education can be understood as efforts to inculcate this attitude into young physicians. It might appear that having physicians with such pro-social, intrinsic motives eliminates the most important agency problem facing doctors: the problem of ensuring that physicians act in the interests of their insured patients. But physicians face more than one agency problem and it is unlikely that the sort of intrinsic motives just described would resolve the agency problem for the insurers and managed care organizations that have the responsibility of paying for care. Indeed, if insurance contracts were such that the patients themselves had to pay the direct cost of their care, they also might prefer a physician whose internal values moved them to balance the marginal benefit of care against its marginal cost.

A deeper, but more speculative, limitation on the use of intrinsic motives to resolve agency problems is that these preferences may not co-exist easily with the use of material incentives. A growing body of theoretical and experimental evidence in economics and psychology points toward the provocative possibility that powerful extrinsic rewards can actually weaken the efficacy of such prosocial motives as altruism, reciprocity, intrinsic motivation and a desire to uphold ethical norms (see Bowles and Polania-Reyes (2010); Bowles and Hwang (2008); and Rebitzer and Taylor (2010); for 
extensive reviews and discussions). ${ }^{14}$ If true, this suggests that organizations that rely on a mix of material incentives and intrinsic motivators might be less efficient than organizations that rely solely on one or the other strategy to resolve agency issues. ${ }^{15}$

To sum up, the economics literature suggests that incentives matter, but that high powered pay for performance schemes may be too blunt a tool for handling the many agency problems that raise the cost and reduce the quality of health care. This depressing conclusion is offset by some more recent results in the organizational economics literature suggesting that it may be possible to resolve agency issues with very low powered incentives by employing physicians in integrated health care delivery organizations. It is to that issue that we now turn.

\section{Professional Autonomy vs. Integration}

Hospitals and physicians together deliver the bulk of medical services in the United States, yet they are strangely divided from each other (Starr 1984). Within hospitals, physician decisions are central to resource allocation and care processes, yet most physicians are quite independent of hospital management, working (as most still do) in small single-specialty groups that they own. Some physicians have "privileges" at more than one hospital and many more split their time and attention between hospital inpatient care and their office-based practices. It is hard to think of another industry - outside of movie making and construction - that relies so heavily on independent contractors as key decision makers. In virtually every industry that, like hospitals, relies on the mass-production of goods or services, key decision makers are either employees of the enterprise or, much more rarely, its owners. Does this

${ }^{14}$ A different, but related, possibility is that high-powered incentives create performance pressures and these pressures are themselves a cause of errors (Ariely et al. 2009). The experiments in this paper ask individuals to perform under incentives that are so powerful as to be outside of the subject's previous experience. For this reason the results may not generalize to physicians or other professionals who are selected for their ability to function in high pressure environments and whose training regularly exposes them to these environments.

${ }^{15}$ Bowles and Hwang (2008, p. 1813) identify a number of ways that material rewards might undermine the prosocial behavior that reduces agency problems. A principal who adopts incentives may communicate belief that his agent is not trustworthy and thereby compromise the agent's predisposition to act in the principal's interest. High powered incentives may compromise the agent's sense of self-determination and so degrade intrinsic motives to "do the right thing". If agents establish their pro-social identity by taking costly actions that benefit others, then lots of incentive pay may make it harder to establish an identity consistent with intrinsic motives. 
difference matter for the efficiency of the health care system? Organizational economics suggests that it might.

For hospitals, the great advantage of having physicians as employees rather than independent contractors is that the employment relationship offers the possibility of resolving agency issues without the distortions created by high powered incentives. This feature of employment relationships has been most clearly analyzed in the context of multi-task models, where agents have more critical tasks to perform than can be included in performance measures. High powered incentives will, in this context, cause the agent to deliver too much of the metered tasks and not enough of the un-metered tasks. Employment relationships offer a straight-forward fix for these multi-task problems because employers have the ability to tell employees the tasks included in their job. By restricting the range of tasks the employee can work on while at work, the employer reduces the opportunity cost of doing the tasks the employer favors. As a result, a small amount of incentive can have a large effect on performance with lower levels of distortion. Put slightly differently, employment relationships differ from market-based relationships in that firms can exert a high degree of influence on employee actions using very little pay for performance (Holmstrom 1999; Holmstrom and Milgrom 1994). The strength of these low-powered incentives is increased when combined with other features of well-run organizations: the careful selection of new employees combined with their subsequent socialization into the goals and procedures of the enterprise. The effectiveness of the combination of appropriate job design, careful selection, socialization and low powered incentives is captured by the term of art used in the management literature, high performance human resource systems (Roberts 2004).

To see the power of weak incentives in the context of employment relationships imagine that a hospital wishes to improve the way in which surgical tools are sterilized and delivered to operating rooms - a surprisingly complicated process that involves surgeons, operating room nurses, hospital managers, and sterilization technicians (Zenios, Surman and Pernas-Giz 2004). Suppose further that operational efficiency can be improved by reducing the number and variety of surgical tools available to surgeons but that negotiating this change involves meetings and consultations with surgeons. If surgeons are 
independent contractors paid per operation, any additional meeting takes time away from the next operation. Attending such a meeting then, is a very expensive task for the surgeon and the surgeon requires equally large benefits in order to be induced to participate. This incentive problem is made worse by the fact that the benefits to the independent surgeon of reducing the number of surgical tools in circulation are clearly less than the benefits accruing to the hospital as a whole, especially if the surgeon divides his operating time across a number of hospitals.

Contrast these incentives with those of a surgeon who is employed by a hospital and is paid on salary. In this setting, attending meetings and participating in improving the sterilization process is not nearly so costly to the surgeon because the opportunity cost of his time is relatively low. These incentives to participate are further strengthened by the relationships the physician builds with co-workers and also by the extent of tacit, firm-specific knowledge, acquired over the course of the employment relationship. ${ }^{16}$

Low-powered incentives of the sort we have discussed can complement higher powered incentives and may help explain the anomalous findings of the Physician Group Demonstration project, an experiment in pay for performance involving large provider groups. Allowing these groups to keep $80 \%$ of their savings (after the first two-percent of savings) elicited only small and uneven cost reductions. As Carrie H. Colla et al. (2012) put it in their analysis of the demonstration project: “The variation both in levels and changes in risk-adjusted spending across organizations was remarkable. We know little about why some succeeded and others failed to achieve savings.” Free-riding can, as we have seen, undermine the incentive effects of conventional pay for performance - but the low-power organizational incentives we have discussed in this section can easily "scale up” for large organizations. It is possible that the variation observed in the demonstration project may be the result of unobserved

16 Jain et al. reports success at reducing multiple drug resistant staph infections (MRSA) through a bundle of practices that included surveillance, isolation, hand-washing and a culture change making every one having contact with the patient responsible for infection control. Implementing this culture change was, likely made easier by the fact that physicians at the VA are also employees of the system. Coordination may also be facilitated when the hospital employing physicians relies on a single, integrated information technology system, although recent empirical investigations find no evidence that investments in information technology improve care quality or reduce the costs of hospital care (Agha 2011). There is, however, some evidence that the use of electronic health records in outpatient settings can improve care quality (Cebul et al. 2011). 
variations in low-powered incentives that can augment under-powered explicit pay for performance incentives. $^{17}$

Given their considerable advantages, why don’t we see hospitals employing physicians and forming large, integrated care delivery systems? In most economic settings, the efficiency advantages of integrated systems should enable them to generate the resources to attract large numbers of physicians and members. What prevents this from happening? Surprisingly little attention has been devoted to this important issue. ${ }^{18}$ The studies that do address it tend to focus on three potential explanations: the nature of economic competition in health care; strategic complementarities between payment systems and health care delivery; and the sociology of the medical profession. We consider each of these in turn. ${ }^{19}$

Regarding economic competition, if payers are unable to measure and reward high value added producers, then it may be that the enhanced efficiency of integrated systems will not translate into a sustainable competitive advantage. Medicare, the biggest single buyer of health care services, does not evaluate the benefits associated with new medical technologies, and it is forbidden from using costeffectiveness analysis and from selectively contracting with more efficient physician groups. Medicare regulatory boards charged with evaluating new technology are concerned primarily with whether new drugs or procedures offer positive benefits (Baicker and Chandra 2011). Private insurance coverage is heavily influenced by Medicare coverage (Baicker and Chandra 2011). In addition, private payers typically use Medicare prices as a reference point in bargaining, and contracts based on value creation are scarce. Indeed it may be that some employers who purchase insurance for employees are not interested in

\footnotetext{
${ }^{17}$ Pay for performance has been reported to have more significant effects in England, see Stephen M. Campbell et al. (2009) and Tim Doran et al. (2011), but it was unclear from these studies how large the physician groups were and whether the incentives were paid to the group or distributed directly to physicians.

${ }^{18}$ In contrast, there has been a large literature documenting the productive and allocative inefficiencies in our care delivery systems. For an incisive review see Baicker and Chandra (2011).

${ }^{19}$ A fourth possibility is that even if measured gains to integrated care delivery systems are large, there might be unobserved costs that swamp these gains. We discuss this possibility when we analyze coordination costs and the rise of hospitalists in section 3 below.
} 
or capable of evaluating the quality of care their employees receive. ${ }^{20}$ The key challenge for the "failure of competition” explanation for the absence of integrated systems is explaining why competition in health care is different than in other sectors where markets do appear able to assess and reward efficient organizational designs.

In contrast, the "strategic complementarities" explanation for the scarcity of integrated health delivery organizations refers to a generic set of explanations for the failure of advanced production methods to defuse rapidly across industries. Indeed much of this work was originally inspired by the difficulties American manufacturers had in imitating and adopting more efficient "lean” manufacturing techniques that originated in Japan and the difficulties firms had in realizing productivity gains from the revolution in information technology (Ichniowski, Shaw and Prennushi 1997; Brynjolfsson and Hitt 2000; and David 1990). Suppose that managers have identified two complementary innovations, A and B. Each innovation on its own produces a small benefit, but introducing A and B simultaneously yields a big improvement in productive efficiency. For concreteness suppose that innovation A involves redesigning job responsibilities in ways that tap the tacit information and problem solving abilities of front line employees to solve customer problems and that innovation B involves hiring more educated workers. Implementing either of these changes is not easy or inexpensive and so it is reasonable to expect firms to experiment with one or the other innovation rather than implementing them both simultaneously. Thus a firm might try action A and be disappointed in the result and therefore not follow-up with step B, hiring a more highly educated work force. Similarly, firms might start with B, but not see much productivity gain because they did not implement step A and redesign job responsibilities in ways that allow the more educated workers to use their superior problem solving and communication skills. It is only when firms

\footnotetext{
${ }^{20}$ In a case study of Geisniger's Provencare program, Clark and Rosenthal quote the results of conversations between Geisinger and the employers who buy their insurance. "We went with the health plan leadership and talked to a number of employers. We told them that we would guarantee delivery of the best care and that we wouldn't submit a bill otherwise. The employers didn't want any of that. Their eyes glazed over. They said, 'As far as we know, we're already buying best practices. The evidence we really care about is whether or not the patients need the procedure in the first place. In addition, we don't like all of the unpredictability in costs that you get with each patient. Give us one price per procedure and you worry about all the other stuff”. (Clark and Rosenthal 2008 p. 8)
} 
reorganize and re-skill the workforce that the powerful complementarities between the two innovations are realized. Put differently, incremental experimentation might not reveal the full productivity benefits of complementarity innovations and so the true value of innovations might not be discovered by managers.

If complementarities can impede innovation within one organization, it becomes even harder when the complementary innovations span multiple organizations, i.e. when innovations are what game theorists call strategic complements. This is Crosson’s (2009) argument for the relative absence of integrated care organizations. He proposes that the full efficiency gains of integrated care delivery can only be realized under bundled prospective payment systems. But in communities with highly fragmented care delivery, it is hard to find providers who can carry the risks entailed by such payments. As a result payers don’t innovate away from the status quo fee-for-service payment system and there is little competitive advantage for providers to move out of their currently fragmented delivery organizations. One of the interesting implications of the "strategic complementarities" explanation is that it offers a natural role for public policy. Specifically, the big public payers (Medicare and Medicaid) can force the issue by announcing that they will be moving towards a bundled prospective payment system that will benefit large integrated organizations. This is the intellectual basis for the Accountable Care Organization initiative we discuss below.

The third explanation for the relative scarcity of integrated care delivery organizations concerns social norms. The simplest version of the social norms explanation is this: physicians value professional autonomy and don't want to be employed by anyone else. There is considerable historical evidence that physicians as a learned profession did and do value their autonomy (Burns, Goldsmith and Muller 2010; Starr 1984). ${ }^{21}$ Unfortunately, this fact alone is not likely to support a satisfactory explanation for fragmented delivery systems. If fragmentation between physicians and hospitals was simply the result of a preference for "being your own boss", then we should observe that physicians working for integrated

\footnotetext{
${ }^{21}$ In private communication, Victor Fuchs suggested to us that medical education plays an important role in propagating norms of professional autonomy - a theme also developed in Gawande (2011).
} 
systems enjoy a significant wage premium to compensate them for the disutility of their status as employees. We are not aware of any study that documents such a pay differential. ${ }^{22}$

More sophisticated models of social norms, however, offer a more promising line of investigation. In models with a more sociological flavor, agents compare their actions with a prescribed set of behaviors (Akerlof 1976, Akerlof 1980) or with the actions of others in their reference groups (Akerlof and Kranton 2000, Akerlof and Kranton 2002). Akerlof and Kranton (2002), for example, argue that individual high school drop-outs are not responsive to the powerful economic gains that accompany graduation from high school because they are averse to adopting behaviors that increase the social “distance” between them and the other drop outs in their group. In this model, shifting away from the high drop-out equilibrium may be most easily accomplished not by adjusting the incentives of any given individual but by a group intervention that causes many of the high-school dropouts to stay in school at the same time.

Similarly in a conventional economic analysis, if a physician decides to work as an employee at a hospital, only the hospital and the physician are involved in the transaction. All else equal, if the hospital offers a pay differential that exceeds the value the physician personally places on autonomy, the physician will choose to abandon the autonomy of her independent practice and go to work as an employee of the hospital. Things work quite differently, however, when norms enter the picture. Norm violating transactions necessarily precipitate actions or changed perceptions (and loss of reputation) by third-party physicians who are not party to the transaction. The involvement of these third parties allows professional norms to persist even when the gains to individuals from violating norms are large relative to their preference for the norm. The involvement of third parties also suggests that stubbornly persistent

\footnotetext{
${ }^{22}$ This is a specific application of the general economic principal of compensating wage differentials. According to this theory, in a competitive labor market, individuals who are employed in odious or risky jobs will have to be compensated for choosing these jobs. Search frictions and other market failures can greatly complicate the measurement of compensating wage differentials (see Lang and Majumdar 2004). So does the presence of social norms as we discuss below.
} 
norms may be greatly weakened by shocks that change the actions or perceptions of many physicians at once. $^{23}$

Just such a change is currently taking place in the medical profession. For most of the $20^{\text {th }}$ century, professional norms in medicine, law and other learned professions were shaped by a labor force composed almost entirely of men, and most of these men had stay-at-home wives (Landers, Rebitzer and Taylor 1996a). In the 1970's, however, women began entering professions in large numbers and today they account for a significant proportion of the labor force in both medicine and law. For our purposes, the significance of this demographic transition is that these new entrants are likely to be influenced by a different set of norms than the male incumbents. Specifically, these women are often married to male professionals who work long hours and they are for this reason quite likely to have to balance norms of medical practice against family responsibilities. Landers, Rebitzer and Taylor (1996a) discuss these issues for the case of lawyers. To the extent that employment in a hospital or other large integrated delivery organization enables physicians to have shorter and more predictable hours than working as an entrepreneur in a small practice, women might be drawn to these positions and this may have the effect of undermining the norm of professional autonomy that has played such an important historical role in the US health care delivery system. ${ }^{24}$

Norms based models of professions shift attention from a narrow focus on individual incentives to a broader view that also includes incentives for action governing the entire profession. From this perspective it is interesting to observe that in the early part of the $20^{\text {th }}$ Century the American Medical Association successfully lobbied for the introduction of "corporate practice of medicine" laws that made

\footnotetext{
${ }^{23}$ In Akerlof's original model of social norms - a model for which he claimed direct relevance to physicians - he even derives an expression for the minimum number of "defectors" from the norm that would be required to cause the norms based equilibrium to collapse (Akerlof 1976).

${ }^{24}$ There is, as yet, not much empirical economics analyzing the ways in which the growth of women in professions alters physician practice norms, although there have been newspaper reports suggesting this (Harris 2011). Landers, Rebitzer and Taylor (1996b) have studied the evolution of work hours in the legal profession as a result of the influx of female lawyers. Their analysis suggests that the evolution of hours may not be a smooth adjustment to the changing composition of the legal labor force. Woman working in professions may also alter the norms under which their sons operate and so, over the long run, switch social norms. Fernandez, Fogli and Olivetti (2004) find that the work experience of mothers-in-law seems to have a big effect on the labor force participation of their daughters in-law.
} 
it illegal for physicians to be employed by other organizations, especially hospitals (Robinson 1999). The legal impact of these laws has diminished over time (as witnessed by the rise of professional hospitalists, an issue we take up below), but their influence is still observed in some states. ${ }^{25}$

If physician professional norms are important for understanding the failure of physician hospital integration in the US, then they might also be important for understanding other market outcomes in health care. Few studies have examined this possibility either empirically or theoretically. An exception is Cooper and Rebitzer (2006). In their model, managed care organizations compete for patients (who are the paying customers) and for physicians to participate in their network of providers. Patients can't directly perceive quality and use as a proxy the number of physicians included in the managed care network. The managed care organizations (MCOs) compete for physicians by offering a combination of salary and cost-containment incentives. MCOs that write contracts with strict cost-control incentives have lower costs and lower premiums but they also have a harder time recruiting physicians to their network of providers than other MCOs do. In equilibrium, MCOs will segment the market. Some will operate with stringent cost-control incentives, small physician panels and low premiums. MCOs in this part of the market profit by attracting cost-conscious customers. Other managed care organizations will have more lax cost-control incentives, bigger provider panels, higher premiums and they profit by attracting customers who put a greater emphasis on provider choice than they do on the cost of insurance. This product differentiation creates disparities in treatment because physicians will use more resources treating policyholders in the high-cost MCOs than the low cost MCOs. Given the many agency problems in this setting, an increase in competition is likely to cause a decline in medical costs - what some have referred to as a "race to the bottom".

Suppose now, that we introduce a physician norm against treatment disparities, perhaps because physicians do not like to deliver care that uses fewer resources than that delivered by other physicians in the market. This norm makes it more difficult for low cost plans to attract physicians and so they must

\footnotetext{
${ }^{25}$ The erosion of these laws does not entirely eliminate legal barriers for hospitals to employ physicians. Arlen and Macleod (Arlen and MacLeod 2003; Arlen and MacLeod 2005) argue that tort law in the United States offers some advantages to hospitals that employ physicians as independent contractors rather than employees.
} 
pay them more (while also reducing cost-containment incentives). With low-cost plans behaving more like high cost plans, there is less product differentiation and no race to the bottom. Indeed heightened competition reduces product differentiation and increases the overall level of resource utilization in the market. In this way, norms of professional practice can help explain why the managed care revolution of the nineties failed to deliver on its promise to control the rise of medical costs. The model also can account for the absence of the widely predicted "race to the bottom" in the managed care market of the 1990 s. $^{26}$

\section{Coordination, Specialization, and Innovation}

The economic ideas we have discussed so far have been primarily concerned with the problem of motivating physicians. A second less well-developed economics literature focuses on problems of coordinating care among physicians who must specialize in specific aspects of care because no single individual can master all medical knowledge.

In his famous dictum that specialization is limited by the extent of the market, Adam Smith neatly summarized the role that markets play in coordinating the activity of highly efficient, specialized producers. More recent work has augmented Smith’s analysis by considering the amount of specialization that will emerge in different economic settings (Becker and Murphy 1992).

Becker and Murphy build a model in which specialization increases the productive efficiency of a team performing complementary tasks. As specialization increases, however, so does the size of the team as well as the costs of coordinating activities among the increasingly specialized producers. These coordination costs are determined by available technologies, especially communication and transportation technologies, but they can also be influenced by agency problems. In Becker and Murphy’s (1992) formulation, increases in the stock of knowledge increase the payoff to team members of investing in

${ }^{26}$ Consistent with this model, Baicker and Chandra (2011 , p. 11) observe that there is a substantial literature showing that practice pattern norms drive similar care for all the patients that a provider sees, regardless of individual insurance status. Burns, Goldsmith and Muller (2010) report that in the 1990s "Health plans found employers reluctant to accept closed panel models that relied on a subset of providers in a given local market. Employees did not want to be forced to switch physicians or hospitals because their employers chose a different health plan. Broad-based health plans, such as preferred provider organizations (PPOs) and point of service pans (POS) triumphed over closed panel HMO plans” p. 50. 
more specialized knowledge. Heightened specialization, it turns out, also increases the payoff to generating new knowledge. Applied to medicine, this framework suggests a positive feedback in which dramatic increases in medical knowledge coincide with dramatic increases in the number of narrow medical sub-specialties.

In a series of papers (Meltzer 2001; Meltzer and Chung 2010b; and Meltzer and Chung 2010a), Meltzer and co-authors have used the tradeoff between coordination costs and specialization to analyze the growth of hospitalists. Hospitalists are a new medical sub-specialty whose purpose is to care for patients when they are hospitalized and then return them to the care of their primary physicians after discharge from the hospital Wachter 2004. Primary care physicians have superior information about their patient's specific situation and handing off in-patient care to hospitalists creates the risk that key information will not be communicated. For this reason, the rise of the hospitalist specialty creates coordination costs that were not present under the traditional US model in which primary care doctors supervised their patient's care in both ambulatory and in-patient settings. Improvements in communication technologies have the effect of reducing coordination costs and thus increasing the demand for hospitalists (Meltzer and Chung 2010b), but this is not the whole story.

Coordination costs are also determined by the switching costs of moving from ambulatory to inpatient settings. It is costly for physicians to switch from office-based care to visiting their hospitalized patients, and some of these costs are fixed (think of the time and effort costs of leaving the office and traveling to the hospital to see patients). In the presence of these fixed switching costs, anything that reduces the number of patients a physician has in the hospital will reduce a primary care physician’s willingness to supervise their patient's inpatient care. For this reason, reductions in hospital length of stay, increases in the use of out-patient procedures in doctors' offices or even a reduction in physician work hours and patient load can have the effect of increasing demand for hospitalists (Meltzer and Chung 2010b; Meltzer and Chung 2010a).

The efficiency gains from specialization are not the only gains from the use of hospitalists. Hospitalists are often employed by hospitals but they may also work as contractors employed by outside 
firms or physician groups (Burns, Goldsmith and Muller 2010). Whatever their formal status, hospitals are likely to have more influence over hospitalist activities then they do over independent, primary care physicians. Hospitals will therefore find their hospitalists relatively easy to engage process improvement initiatives. By the same token, however, hospitals might use this heightened influence to encourage their hospitalists to shift costs onto other parts of the health care system. Recent findings about the effect of treatment by hospitalists on Medicare patients give some cause for concern in this regard. Kuo and James S. Goodwin (2011), find that Medicare patients treated by hospitalists are associated with reduced length of stay and hospital charges but higher Medicare costs 30 days after discharge as well as higher readmission rates

The models of specialization we have so far discussed are appealing, but they do not consider the referral patterns we observe in medicine. In medicine, primary care providers are generalists trained to recognize and treat common and less difficult conditions. When less common or more difficult patients arrive, the primary care physicians refer them to specialists who have the extra training and experience required to handle these cases. Garicano (2000) identifies conditions under which this sort of referral process is optimal. This model can also be used to generate predictions about how the work of primary care providers and specialists should vary with changes in cost parameters. A fall in the time and effort cost of communication with specialists increases the number of conditions that primary care physicians will refer to specialists while a fall in the costs of learning about rare conditions (via internet search for example) broadens the number of cases the primary care providers will handle themselves.

The process of referral from generalist to specialist creates an agency problem. Consider for example a patient who approaches her primary care doctor for treatment for a rash. The primary care physician can either refer the patient to a dermatologist or treat the condition themselves and generate extra revenues. If the dermatologists' in-depth knowledge leads to superior and cost-effective treatment, the referral is efficient. Efficient referrals may not occur, however, if the primary care physician loses too 
much revenue by referring the patient. ${ }^{27}$ While there may be little concern that an internist will fail to refer a breast cancer patient to a breast surgeon and oncologist, there are a very large number of conditions that fall into a gray area where the skills and knowledge of the generalist and specialist overlap. $^{28}$

Garicano and Santos (2004) analyze the incentives for optimal referrals in the context of professional services. ${ }^{29}$ They find that in "bottom up" settings like medicine where generalists make the decision to refer to more highly trained specialists, professional partnerships may have a distinct advantage. This is because the revenue sharing agreements in these partnerships allow the referring primary care doctor to earn some money from the fees the specialist generates. Their theory suggests that to best realize the advantages of efficient referrals, multi-specialist groups ought to be composed of physicians working in areas where agency issues are likely to arise. Thus there might be good incentive reasons to include internists and dermatologists in the same group, but not cardiac surgeons. To our knowledge, no studies have investigated the predictions of Garicano and Santos (2004) as they apply in the context of multi-specialty groups. ${ }^{30}$

Alternatively, even in single-specialty groups, larger groups could help foster efficient matching of higher-risk patients to physicians with specialized skills in a particular area of care. In an interesting

${ }^{27}$ Over referral is also possible if the primary care doctor addresses the rashes in a more cost-effective manner than the specialist, but does not receive sufficient compensation.

${ }^{28}$ Conditions in this grey area might include asthma, moderate depression, sprains of various sorts and even chest pain. In an empirical demonstration of such a gray area, Afendulis and Kessler (2007), find substantial differences in treatment patterns for interventional cardiologists (who can perform angioplasties) to non-interventional cardiologists (who cannot), with lower rates of referral for bypass surgery and lower rates of nonsurgical treatment (e.g. drug therapy) in the former group.

${ }^{29}$ Garicano and Santos (2004) do not consider another sort of agency problem arising from referrals, whether physicians do a good job evaluating the quality of specialists to whom they refer patients. In studying the referral patterns to cardiac surgeons, Epstein (2010), finds evidence that referring physicians were (on average) knowledgeable about the relative quality of surgeons. Similarly, Johnson (2011) finds that very low quality cardiac specialists are more likely to stop practicing or change medical markets, which also is consistent with informed referrals to higher quality specialists.

${ }^{30}$ A full test of the model must consider as well that the referral advantages of large multi-specialty groups needs to be balanced against the free-riding problems that also increase with group. 
application of this idea, Andrew Epstein, Jonathan Ketchum and Sean Nicholson (2010) show that highrisk obstetrics patients treated in a group practice are more likely to match with an appropriate specialist than are patients of solo practitioners, which leads to better health outcomes. Their results are consistent with the predictions of Garicano and Santos (2004) that firms facilitate matching and specialization. ${ }^{31}$

As we have already observed, innovation in health care has resulted in a division of labor in which specialists with advanced training focus on the most difficult and advanced sort of medical practice. Christensen, Grossman and Hwang (2009), however, argue that innovations in treating the most common and routine sorts of care might also be very important.

Christensen, Grossman and Hwang (2009) observe that health care delivery in the US must be concerned with treating two very different kinds of medical issues. One the one hand, there are the difficult, hard to assess cases that require sophisticated pattern recognition and non-routine decision making by the physician (think, here, of the many conditions featured on the TV show House whose etiology or treatment protocol is murky). On the other hand, there are the familiar cases whose treatment can be handled by clear, evidence-based protocols. In the typical physician practice, the responsibility for both of these cases falls to the physician. This division of labor makes some sense as individual patients can unexpectedly acquire one or the other type of condition, and their primary care physician is in an excellent position to coordinate care across both these types of issues. But, according to Christensen, Grossman and Hwang (2009) this approach to coordinating care also increases costs and dampens important innovation. Care for the protocol based conditions, if broken out of the physician's practice, will be less expensive because the caregiver is not an expensive or highly-trained generalist. In addition, organizations that specialize in protocol-based care for common issues can use the techniques of modern management to implement continuous improvement processes that drive down costs and improve

\footnotetext{
${ }^{31}$ Interestingly, Epstein, Ketcham and Nicholson (2010), find that rates of specialization are similar across obstetricians in solo and group practice. This suggests that obstetrics markets allow sufficient coordination across distinct practices to encourage specialization, but that firms are able to improve on this.
} 
effectiveness. The job of implementing these techniques will be made simpler by the fact that physicians will not play a central role in these organizations. ${ }^{32}$ More provocatively, Christensen, Grossman and Hwang (2009) cite evidence from other industries suggesting that innovations originating in the low-cost, low-prestige parts of an industry often end up transforming the production processes required for highend goods and services as well. If this pattern holds true for medicine, improvements in the delivery of care through "mini-clinics" and other limited care delivery operations may end up increasing the rate of innovation in the entire industry.

\section{Prospects for Accountable Care Organizations.}

Accountable Care Organizations (ACOs) are an organizational innovation created as part of the Medicare Shared Savings Program of the Patient Protection and Affordable Care Act that was signed into law by President Obama in 2010. Although ACOs are only a small part of a huge piece of legislation, they have attracted a great deal of attention from policy-makers, physicians and managers. ${ }^{33}$

ACOs are a network of hospitals and providers that contract with the Center for Medicare and Medicaid Services (CMS) to provide care to a large bloc of Medicare patients (5,000 or more). ${ }^{34}$ The contracts, which last for three years, create a single risk-bearing entity with incentives to control costs. ACOs that come in under their specified cost benchmarks earn a fraction of the savings. In order to

\footnotetext{
${ }^{32}$ The notion that some types of innovation are best pursued in specific types of organizations is not unique to health care. Roberts (2004) describes the difficulties of encouraging exploratory research in organizations focused on tightly controlled incremental innovation processes and the benefits that may result from placing the exploratory innovation in a bureaucratically isolated "skunk works".

${ }^{33}$ As an indication of the interest in ACOs, consider the following incomplete list of articles over the past year or so in such leading journals as the New England Journal of Medicine, The Journal of the American Medical Association and Health Affairs (Crosson, Shields et al. 2011, Shortell, Casalino and Fisher 2010, Singer and Shortell 2011, Ginsburg 2011, Zirui Song et al. 2011 )

34 ACO-like arrangements need not be limited to Medicare. Zirui Song et al. (2011) analyze the effects of a global double sided payment incentive system implemented by Blue Cross Blue Shield of Massachusetts. The contract was similar in many respects to the shared savings program for Medicare but instead of Medicare patients it was implemented for HMO and point of service commercial populations. The study reports that the new contract slowed spending growth modestly in its first year of operation and improved care quality. The cost savings were largely achieved through changes in referral patterns (shifts in outpatient care toward facilities with lower fees, from lower expenditures for procedures, imaging and testing; and from a reduction in spending for enrollees with the highest expected spending) rather than through changes in utilization.
} 
receive these payments the ACO must also meet stringent standards on 65 quality indicators that reflect patient and caregiver experience, care coordination, patient safety, preventative health, and health of atrisk frail and elderly populations (Ginsburg 2011). Ginsberg summarizes the intent of the compensation system nicely

"Built on a fee-for-service chassis, but with unrestricted patient choice, safeguards to prevent stinting on needed care, and quality standards, the Medicare Shared Savings Program attempts to avoid the pitfalls of capitation but still offer ACOs a financial upside if they reduce costs relative to a benchmark and report strong results on quality metrics. (Ginsburg 2011, p.2085).

It is interesting to consider the ACO experiment from the perspective of organizational economics. ${ }^{35}$ For the statistical reasons we discussed in section I, ACOs must enroll large numbers of Medicare patients in order to generate reliable measures of savings (Fisher et al. 2009). But, as we have emphasized, implementing pay for performance in large groups creates free-riding problems that can dramatically weaken incentives. Put differently, if the ACO is comprised of independent contractor physicians connected only by a common hospital and a common incentive plan, they are unlikely to achieve the desired changes in provider behaviors. Selection, socialization, training and careful job design are what gives a large organization the ability to influence the behavior of physicians in large groups. If these elements are missing, it is hard to see ACOs having much effect on the way health care is delivered.

In order to achieve savings, the ACO has to manage the capabilities of hospitals and the primary care physicians who make up of the ACO. The most straightforward way to manage these very different capabilities would be for hospitals to simply employ physicians, but as we have discussed there are historical, legal, strategic and sociological obstacles to achieving this goal. Simply purchasing physician practices, as many hospitals and PHOs did during the 1990s, will not do the trick, but it may not be

\footnotetext{
${ }^{35}$ This, of course, is not the only relevant perspective from which to view ACOs. It may be that ACOs, like physician hospital organizations, increase the bargaining power of hospitals. Gaynor and Town (2012) cite evidence from the UK and the US that increased hospital concentration leads to both higher prices and lower quality - especially when there are administered prices. To the extent that ACOs reduce competition for patients they may have similar deleterious effects and it may be that these more than offset gains from incentives to improve care coordination.
} 
necessary for ACOs to employ all their primary care physicians. Some organizations appear to be able to incorporate a significant number of non-employed physicians into ACO-like arrangements and this offers some hope for expanding the range of hospital-physician coordination. ${ }^{36}$ A critical element in these organizations is to build legitimacy among independent physicians by making them part of the governance of the organization.

Incorporating specialists into the ACO will be challenging because specialists are not required to limit themselves to a single ACO (Singer and Shortell 2011). The referral model of Garicano and Santos 2004 suggests that ACOs can reduce referrals by introducing training and computer assisted decision support that make it easier for generalists to substitute their own decisions for those of the specialists. It may, for example, be better to train primary care physicians to treat rashes and acne rather than sending every case of rash or acne to a dermatologist. On the other hand, the vast explosion in medical knowledge implies that there are limits to the substitution of generalist for specialist care. In this case, Garicano and Santos (2004) analysis suggests that efficiently managing referrals to specialists will likely entail bringing some specialists into the ACO. Keeping these specialists fully occupied will also exert upward pressure on the optimal scale of ACOs.

Frandsen and Rebitzer (2013a) present theory and evidence that the pay for performance incentives in ACOs will necessarily be under-powered, that is they will be too weak to elicit meaningful changes in behavior. From this perspective it is helpful to think of the ACO’s incentive problem as analogous to the provision of effort when effort is a public good. In their extensive review of the experimental literature on public goods provision, Bowles and Polania-Reyes (2010) conclude that the effects of incentives on public good provision depend critically on the meaning agents give to the incentive. They speculate that well-designed incentives should be implemented in a way that helps the agent understand that "the desired modification in her actions will serve to implement an outcome that is socially beneficial so that the target is more likely to endorse the purpose of the incentive, rather than

\footnotetext{
${ }^{36}$ Shields et al. (2011) describe how Advocate Physician Partners in Illinois combined a system of 10 hospitals and 800 physician employees with a network of 2700 independent physicians. Their discussion emphasizes the importance of having physicians play a leadership role in the governance of the organization.
} 
being offended by it as either unjust or a threat to her autonomy...”. ${ }^{37}$ Extending this logic to the case of intrinsically motivated physicians; managing ACOs likely involves paying careful attention to assigning meaning to the payments, but it is unclear if this meaning is more easily constructed within conventional employment relationships or within hybrid organizations in which doctors participate under looser arrangements. Given the medical profession's long history of battling to preserve its status as an autonomous and learned profession, low powered incentives in ACOs built upon a hybrid organizational form might be workable. On the other hand, conventional organizations may have greater opportunities to train, screen and socialize for physicians who might respond well to low-powered incentives.

To the extent that successful ACO’s have organizational capabilities that rely on training, screening, socialization and constructing the "meaning” of incentives they likely also involve relational contracts. Relational contracts are based upon informal trusting arrangements whose credibility is enforced by the continuing value of the relationship between parties (Gibbons and Henderson 2011). The great advantage of relational contracts for ACOs is that they can complement more formal relationships such as those involved in pay for performance. Incentives that would be under-powered in the sense of a principal-agent model may be quite a bit more effective if performance this period determined the continuation of a valuable on-going relationship. ${ }^{38}$ Relational contracts can also be used to reduce some of the distortions of high-powered formal incentives. ${ }^{39}$

Taken together, our analysis suggests that as a policy intervention, ACOs are likely to have the biggest effect where care is already integrated. Advocates of ACOs know this and see ACOs as emerging

\footnotetext{
${ }^{37}$ This point is echoed in the growing literature on behavioral agency theory. See Rebitzer and Taylor (2010) and Ellingsen and Johannesson (2007) for extensive reviews and discussions.

${ }^{38}$ The value of an on-going relationship can be enhanced simply by increasing the fixed component of compensation as in efficiency wage models or by back-loading compensation to create implicit performance bonds.

${ }^{39}$ Production workers at Lincoln Electric, for example, received a weekly salary determined entirely by piece rates. These high piece rates produced a furious work pace and high worker earnings, but they also made it difficult to experiment with new production methods or quality improvements because any change that interfered with production cost workers money. This undesirable side-effect of high-powered piece rate incentives was partly offset by a very large annual bonus that was distributed to production workers based on managers' subjective assessment of their willingness to cooperate and help improve the overall functioning of the enterprise. Maintaining the value of the subjective performance assessments gave managers the incentive to use these in a value creating manner (Gibbons and Henderson 2011).
} 
from five different practice arrangements. In order of ease of implementation these are: integrated delivery systems that combine insurance, hospitals, and physicians; multi-specialty group practices; physician hospital organizations; independent practice associations, and virtual physician organizations (Shortell, Casalino and Fisher 2010).

Shortell, Casalino and Fisher (2010) argue for looser criteria for ACOs emerging from less supportive institutional settings. This recommendation makes sense if the primary obstacle to the formation of integrated organizations was strategic complementarities, i.e. the absence of a big payer willing to employ prospective payment systems. This recommendation may not be right, however, if the primary barrier to integrated care comes from the difficult organizational issues we have highlighted in this essay. Encouraging the formation of ACOs which have no hope of successfully altering care patterns creates entities whose only rationale would be to bargain harder with insurers - an outcome that would enrich providers at the expense of the rest of society.

\section{Conclusions}

In this essay we have applied the conceptual tool-kit of organizational economics to the economics of physician practices. Our discussion has focused on three broad themes from organizational economics: principal agent problems (both conventionally economic and behavioral); inefficiencies in the market for organizational form (resulting from social norms and various market failures); and the tradeoff between the productivity gains from specialization and the coordination costs specialization entails.

We have applied these themes to important features of physician practices. Much of our attention has focused on understanding the stubborn persistence of fragmented care delivery via small, physician owned practices, but we have considered other important issues as well. These include: the mixed record of pay for performance - especially in large health care organizations; the difficulties of achieving efficient levels of referrals between generalized and specialized providers; and the emergence of a fastgrowing new medical specialty, hospitalists, as a result of changes in the tradeoffs between specialization and coordination costs. In the final section, we brought all the themes together in an assessment of the 
prospects for Accountable Care Organizations, an important public policy initiative in the United States aimed at reforming both incentive systems and the organizational forms within which care is provided. In each of our applications we found that the ideas of organizational economics yielded genuine and sometimes unexpected insights. This gives us some confidence that the idiosyncratic features of physician practices do not invalidate insights gleaned from the study of other, more standard, economic entities. In the long-struggle to improve health care efficiency, organizational economics will likely help providers, managers and policy makers better understand how best to coordinate and motivate the physicians who guide patient care. 



\section{Table 1: Physicians Characteristics over Time}

\begin{tabular}{|c|c|c|c|c|c|c|c|}
\hline & \multicolumn{7}{|c|}{ Year } \\
\hline & 1949 & 1960 & 1970 & 1980 & 1990 & 2000 & 2008 \\
\hline MDs per 10,000 population ${ }^{\mathrm{a}}$ & 14.1 & 14.5 & 16.4 & 20.6 & 24.7 & 28.9 & 31.4 \\
\hline Active MDs per 10,000 population & 12.8 & 13.8 & 15.3 & 18.3 & 22.0 & 24.6 & 25.8 \\
\hline pct general practice/family medicine & 50.1 & 35.6 & 18.6 & 14.5 & 12.9 & 12.5 & 12.0 \\
\hline pct other primary care & 15.0 & 21.1 & 24.6 & 26.7 & 26.1 & 27.2 & 27.0 \\
\hline Percent female $^{b}$ & & & 7.1 & 11.4 & 17.2 & 25.2 & 31.2 \\
\hline Mean hours worked per week ${ }^{\mathrm{c}}$ & & & & 53.5 & 53.4 & 51.4 & $49.6(2007)$ \\
\hline male & & & & 54.8 & 54.8 & 53.4 & 51.7 \\
\hline female & & & & 41.3 & 46.0 & 44.8 & 44.4 \\
\hline self-employed & & & & 53.5 & 54.3 & 52.1 & 50.9 \\
\hline employed & & & & 53.4 & 51.8 & 51.0 & 49.0 \\
\hline
\end{tabular}

a Source: National Center for Health Statistics 2011. Prior to 1970, MDs with unknown address or unclassified primary specialty were counted among active MDs. Starting in 1970, MDs with unknown address or unclassified primary specialty were not counted as active. Percent "other primary care" includes primary care specialties of internal medicine, obstetrics/gynecology and pediatrics. Count of primary care physicians in obstetrics/gynecology is unavailable prior to 1970. Table assumes 6.0 percent of active physicians were in obstetrics/gynecology in 1949 and 1960, consistent with the fraction in 1970 (6.0 percent) and in 1980 (5.9 percent).

${ }^{\mathrm{b}}$ Source: American Medical Association (various years). Reflects percent female among active MDs.

${ }^{\mathrm{c}}$ Source: Current Population Survey, as reported by Staiger et al. (2010) for non-resident physicians. 
Table 2: Changes in Care Delivery Settings

\begin{tabular}{|c|l|l|l|l|l|l|l|l|}
\hline & \multicolumn{9}{|c|}{ Year } & $\mathbf{1 9 9 5}$ & $\mathbf{2 0 0 0}$ & $\mathbf{2 0 0 5}$ & $\mathbf{2 0 0 8}$ \\
\hline & $\mathbf{1 9 7 5}$ & $\mathbf{1 9 8 0}$ & $\mathbf{1 9 8 5}$ & $\mathbf{1 9 9 0}$ & $\mathbf{1 9 9 5}$ & \\
\hline Hospital-based care & & & & & & & & \\
\hline Admissions (per 100 population) & 16.7 & 17.1 & 15.3 & 13.5 & 12.7 & 12.4 & 12.5 & 12.3 \\
\hline Mean length-of-stay & 11.4 & 10.0 & 9.1 & 9.1 & 7.8 & 6.8 & 6.5 & 6.3 \\
\hline Outpatient visits (per capita) & 1.18 & 1.16 & 1.19 & 1.48 & 1.84 & 2.10 & 2.28 & 2.33 \\
\hline & & & & & & & & \\
\hline Office-based care & & & & & & & & \\
\hline Visits (per capita) & 2.69 & 2.63 & 2.67 & 2.82 & 2.65 & 2.92 & 3.26 & 3.14 \\
\hline primary care visits (per capita) & 1.85 & 1.74 & 1.66 & 1.79 & 1.63 & 1.72 & 1.92 & 1.87 \\
\hline specialist visits (per capita) & 0.84 & 0.89 & 1.01 & 1.03 & 1.02 & 1.20 & 1.34 & 1.27 \\
\hline
\end{tabular}

Note: Hospital outpatient visits include visits to the emergency room, hospital outpatient departments, referred visits (pharmacy, EKG, radiology), and outpatient surgeries.

Source: National Center for Health Statistics 2011. 
Table 3: Trends in Employment and Group Size, to 2001

\begin{tabular}{|c|c|c|c|c|c|c|c|c|}
\hline & \multicolumn{8}{|c|}{ Year } \\
\hline & $1975^{\mathrm{a}}$ & $1983^{\mathrm{a}}$ & $1988^{b}$ & $1991^{b}$ & $1994^{\mathrm{b}}$ & $1997^{b}$ & $1999^{\mathrm{C}}$ & $2001^{\mathrm{C}}$ \\
\hline \multicolumn{9}{|c|}{ Panel A: Employment } \\
\hline Self-employed & & 75.8 & 72.1 & & 57.7 & & 62.0 & 65.5 \\
\hline solo practice & & 40.5 & 38.5 & & 29.3 & & 26.4 & 24.4 \\
\hline Employee & & 24.2 & 27.9 & & 42.3 & & 38.0 & 34.5 \\
\hline group practice & & & 7.8 & & 14.6 & & 8.6 & 8.4 \\
\hline institutional & & & 20.1 & & 27.7 & & 29.4 & 26.1 \\
\hline hospital & & & 4.1 & & 6.7 & & 7.7 & 7.7 \\
\hline medical school & & & 5.6 & & 8.2 & & 7.7 & 7.4 \\
\hline HMO & & & 2.3 & & 4.1 & & 2.6 & 1.8 \\
\hline state/local govt & & & 4.7 & & 3.2 & & 3.2 & 2.4 \\
\hline other & & & 3.3 & & 5.5 & & 8.2 & 6.8 \\
\hline \multicolumn{9}{|l|}{ Panel B: Group Size } \\
\hline solo practice & 54.2 & 48.9 & & & & & & \\
\hline 2 physicians & 14.1 & 12.5 & & & & & & \\
\hline 3-7 physicians & 21.3 & 24.3 & & & & & & \\
\hline 8-25 physicians & 6.0 & 8.8 & & & & & & \\
\hline 25+ physicians & 4.5 & 5.3 & & & & & & \\
\hline \multicolumn{9}{|c|}{ (1988-2001 categories) } \\
\hline solo practice & & & 49.3 & 45.5 & 42.9 & 39.0 & 37.7 & 33.2 \\
\hline 2-4 physicians & & & 27.2 & 29.0 & 28.2 & 25.8 & 25.5 & 26.4 \\
\hline 5-9 physicians & & & 11.6 & 13.2 & 14.7 & 16.6 & 15.5 & 16.3 \\
\hline 10-49 physicians & & & 8.1 & 8.8 & 10.7 & 13.8 & 15.2 & 17.0 \\
\hline 50+ physicians & & & 3.8 & 3.5 & 3.5 & 4.8 & 6.2 & 7.2 \\
\hline
\end{tabular}

Note: Employment statistics refer to nonfederal post-GME patient care physicians. Self-employed physicians are defined as those with full or part ownership in their main practice. Institutional employee category "other” includes physicians practicing in community health centers, freestanding clinics and independent contractors in other institutional settings. Group size statistics additional restricted to physicians in solo or group practice. 
a Source: (1975) AMA Periodic Survey of Physicians and (1983) AMA Socioeconomic Monitoring System. Employment statistics as reported in Kletke, Emmons and Gillis 1996. Practice size statistics as reported in Ohsfeldt 1983.

${ }^{\mathrm{b}}$ Source: AMA Socioeconomic Monitoring System. Employment statistics as reported in Kletke, Emmons and Gillis 1996. Practice size statistics as reported in Kletke 1998.

c Source: AMA Socioeconomic Monitoring System, as reported by Kane 2004a.

${ }^{\mathrm{d}}$ Source: AMA Patient Care Physician Survey, as reported by Kane 2004b. 
Table 4: Recent Trends in Employment, Practice Setting and Group Size, 1996-2008

\begin{tabular}{|c|c|c|c|c|c|}
\hline & \multicolumn{5}{|c|}{ Year } \\
\hline & $1996-97^{\mathrm{a}}$ & $1998-99^{a}$ & $2000-01^{a}$ & $2004-05^{a}$ & $2008^{b}$ \\
\hline \multicolumn{6}{|l|}{ Panel A: Employment } \\
\hline Self-employed & 61.6 & 56.7 & 55.9 & 54.4 & 56.3 \\
\hline solo/2-physician practice & 37.4 & 33.6 & 31.2 & 28.1 & 28.5 \\
\hline Employee & 38.4 & 43.3 & 44.1 & 45.6 & 43.7 \\
\hline \multicolumn{6}{|l|}{ Panel B: Practice Setting } \\
\hline Solo/group practice & 68.9 & 64.7 & 65.4 & 64.1 & 72 \\
\hline Hospital & 10.7 & 12.6 & 12 & 12 & 13.1 \\
\hline Medical School & 7.3 & 7.7 & 8.4 & 9.3 & 7.3 \\
\hline HMO & 5 & 4.6 & 3.8 & 4.5 & 3.5 \\
\hline Other & 8.3 & 10.5 & 10.4 & 10.1 & 4.1 \\
\hline \multicolumn{6}{|l|}{ Panel C: Group Size } \\
\hline Solo/2-Physician Practices & 59.1 & 57.8 & 53.8 & 50.7 & 44.4 \\
\hline 3 to 5 Physician Practices & 17.7 & 14.8 & 17.9 & 15.3 & 20.1 \\
\hline 6 to 50 Physician Practices & 19.0 & 21.9 & 24.2 & 27.5 & 26.9 \\
\hline$>50$ Physician Practices & 4.2 & 5.4 & 4.1 & 6.6 & 8.5 \\
\hline
\end{tabular}

Note: Statistics calculated to be nationally representative of all non-federal physicians who spend at least 20 hours a week in direct patient care. Self-employed physicians are defined as those with full or part ownership in their main practice. Practice setting category "Other" includes physicians practicing in community health centers, freestanding clinics and other settings, as well as independent contractors. Group size statistics restricted to physicians in solo or group practice.

${ }^{a}$ Source: Community Tracking Study Physician Survey. See Liebhaber and Grossman 2007for details. ${ }^{\mathrm{b}}$ Source: HSC 2008 Health Tracking Physician Survey. See Boukus, Cassil and O'Malley 2009 for details. 


\section{Bibliography}

Afendulis, C. C. and D. P. Kessler (2007). "Tradeoffs from Integrating Diagnosis and Treatment in Markets for Health Care." American Economic Review 97(3): 7.

Agha, L. (2011). The Effects of Health Information Technology on the Costs and Quality of Medical Care, Massachusetts Institute of Technology.

Akerlof, G. A. (1976). "The Economics of Caste and of the Rat Race and Other Woeful Tales." Quarterly Journal of Economics 90(4): 599-617.

Akerlof, G. A. (1980). "A Theory of Social Custom, of Which Unemployment May be One Consequence." The Quarterly Journal of Economics 94(4): 749-775.

Akerlof, G. A. and R. E. Kranton (2000). "Economics and Identity." Quarterly Journal of Economics 115(3): 715-753.

Akerlof, G. A. and R. E. Kranton (2002). "Identity and Schooling: Some Lessons for the Economics of Education." Journal of Economic Literature 40(4): 1167-1201.

American Hospital Association, H. F. (2010). A.H.A. Hospital Statistics. Chicago, IL, American Hospital Association.

American Medical Association Physician Characteristics and the Distribution in the United States. Washington DC, American Medical Association Press.

Ariely, D., U. Gneezy, et al. (2009). "Large Stakes and Big Mistakes." Review of Economic Studies 76(2): 451-469.

Arlen, J. and W. B. MacLeod (2003). "Malpractice Liability for Physicians and Managed Care Organizations." 2003 New York University Law Review New York University Law Review: 1929-2006.

Arlen, J. and W. B. MacLeod (2005). "Torts, Expertise, and Authority: Liability of Physicians and Managed Care Organizations." RAND Journal of Economics 36(3): 494-519.

Baicker, K. and A. Chandra (2011). Aspirin, Angioplasty, and Proton Beam Therapy: The Economics of Smarter Health Care Spending. Jackson Hole Economic Policy Symposium.

Bazzoli, G. J., L. Dyan, et al. (2004). "Two Decades of Organizational Change in Health Care: What Have we Learned?" Medical Care Research and Review 61(3): 247-331.

Becker, G. S. and K. M. Murphy (1992). "The Division of Labor, Coordination Costs, and Knowledge." Quarterly Journal of Economics 107(4): 1137-1160.

Blumenthal, D. (2004 ). "New Steam from an Old Cauldron - The Physician Supply Debate." New England Journal of Medicine 350: 1780-1787.

Boukus, E. R., A. Cassil, et al. (2009). A Snapshot of U.S. Physicians: Key Findings from the 2008 Health Tracking Survey. Data Bulletin. Washington DC, Center For Studying Health System Change.

Bowles, S. and S.-H. Hwang (2008). "Social Preferences and Public Economics: Mechanism Design When Social Preferences Depend on Incentives." Journal of Public Economics 92(8-9): 18111820.

Bowles, S. and S. Polania-Reyes (2010). "Economic Incentives and Pro-social Preferences as Complments or Substitutes."

Brynjolfsson, E. and L. M. Hitt (2000). "Beyond Computation: Information Technology, Organizational Transformation and Business Performance." Journal of Economic Perspectives 14(4): 23-48.

Burns, L. R., J. C. Goldsmith, et al. (2010). Chapter Two: History of Physician-Hospital Collaboration. Partners in Health: How Physicians and Hospitals Can be Accountable Together. F. J. Crosson and L. A. Tollen. San Francisco California, Jossey-Bass.

Carrie H. Colla, P., M. David E. Wennberg, MPH, et al. (2012). "Spending Differences Associated with the MEdicare Physician Group Practice Demonstration." Journal of the American Medical association 308(10): 1015-1023.

Cebul, R., J. B. Rebitzer, et al. (2008). "Organizational Fragmentation and Care Quality in the US Health Care System." Journal of Economic Perspectives 22(4): 93-113. 
Cebul, R. D., T. E. Love, et al. (2011). "Electronic Health Records and Quality of Diabetes Care." New England Journal of Medicine.

Christensen, C. M., J. H. Grossman, et al. (2009). The Innovator's Prescription : A Disruptive Solution for Health Care, McGraw-Hill.

Clark, J. and M. Rosenthal (2008). ProvenCare: Geisinger Health System and Pay for Performance. Harvard School of Public Health. Boston, Harvard University.

Cooper, D. J. and J. B. Rebitzer (2006). "Managed Care and Physician Incentives: The Effects of Competition on the Cost and Quality of Care." B.E. Journals in Economic Analysis and Policy: Contributions to Economic Analysis and Policy 5(1): 1-30.

Cooper, R. A., T. A. Getzen, et al. (2002). "Economic and Demographic Trends Signal an Impending Physician Shortage." Health Affairs 21(1): 140-154.

Crosson, F. J. "The Accountable Care Organization: Whatever Its Growing Pains, The Concept Is Too Vitally Important To Fail." Health Affairs 30(7): 1250-1250-1255.

Crosson, F. J. (2009). "21st Century Health Care- The Case for Integrated Delivery Systems." New England Journal of Medicine 36(14): 2.

David, P. A. (1990). "The Dynamo and the Computer: An Historical Perspective on the Modern Productivity Paradox." American Economic Review 80(2): 355-361.

Ellingsen, T. and M. Johannesson (2007). "Paying Respect." Journal of Economic Perspectives 21(4): 135-140.

Encinosa, W. E., M. Gaynor, et al. (2007). "The sociology of groups and the economics of incentives: Theory and evidence on compensation systems." Journal of Economic Behavior \& Organization 62(2): 187-214.

Epstein, A. J. (2010). "Effect of Report Cards on Referral Patterns to Cardiac Surgeons." Journal of Health Economics 29: 23.

Epstein, A. J., J. D. Ketcham, et al. (2010). "Specialization and matching in professional service firms." Rand Journal of Economics 41(4): 23.

Fernandez, R., A. Fogli, et al. (2004). "Mothers and Sons: Preference Formation and Female Labor Force Dynamics." Quarterly Journal of Economics 119(4): 1249-1299.

Fisher, E. S., M. B. McClellan, et al. (2009). "Fostering Accountable Health Care: Moving Forward In Medicare." Health Affairs 28(02782715): W219-W219-W231.

Frandsen, B. and J. B. Rebitzer (2013a). Structuring Incentives in Organizations: The Case of Accountable Care Organizations, Boston University School of Management Working Paper

Frandsen, B. and J. B. Rebitzer (2013b). "Structuring Incentives Within Organizations: The Case of Accountable Care Organizations." Boston University School of Management Working Paper.

Garicano, L. (2000). "Hierarchies and the Organization of Knowledge in Production." Journal of Political Economy 108(5): 874-904.

Garicano, L. and T. Santos (2004). "Referrals." American Economic Review 94(3): 499-525.

Gawande, A. (2011). "Cowboys and Pit Crews." New Yorker.

Gaynor, M. and P. J. Gertler (1995). "Moral Hazard and Risk Spreading in Partnerships." RAND Journal of Economics 26(4): 591-613.

Gaynor, M., J. B. Rebitzer, et al. (2004). "Physician Incentives in Health Maintenance Organizations." Journal of Political Economy 112(4): 915-931.

Gaynor, M. and R. Town (2012) "The Impact of Hospital Consolidation-Update." The Synthesis Project.

Gibbons, R. and R. Henderson (2011). "Relational Contracts and Organizational Capabilities." Organization Science (forthcoming).

Ginsburg, P. B. (2007). "Shopping for Price in Medical Care." Health Affairs 26(2): w208-w216.

Ginsburg, P. B. (2011). "Spending to Save - ACOs and the Medicare Shared Savings Program." New England Journal of Medicine 364(22): 2.

Harris, G. (2011). As Physicians Jobs Change, So Do Their Politics. New York Times. New York City. 
Holmstrom, B. (1999). "The Firm as a Subeconomy." Journal of Law, Economics, and Organization 15(1): 74-102.

Holmstrom, B. and P. Milgrom (1994). "The Firm as an Incentive System." American Economic Review 84(4): 972-991.

Ichniowski, C., K. Shaw, et al. (1997). "The Effects of Human Resource Management Practices on Productivity: A Study of Steel Finishing Lines." American Economic Review 87(3): 291-313.

Jain, R., S. M. Kralovic, et al. "Veterans Affairs Initiative to Prevent Methicillin-Resistant Staphylococcus aureus Infections." New England Journal of Medicine 364(15): 1419-1430.

Johnson, E. M. (2011). Ability, Learning and the Career Path of Cardiac Specialists. Cambridge, Massachusetts Institute of Technology.

Kane, C. K. (2004a). The Practice Arrangements of Patient Care Physicians, 1999 Revised,. Physician Marketplace Report. Chicago, American Medical Association.

Kane, C. K. (2004b). The Practice Arrangements of Patient Care Physicians, 2001. Physician Marketplace Report. Chicago, American Medical Association.

Kane, G. C., M. R. Grever, et al. (2009). "The Anticipated Physician Shortage: Meeting the Nation’s Need for Physician Services." American Journal of Medicine 122(12): 1156-1162.

Kim, D. (2011). Medicare Payment Reform and Hospital Costs: Evidence from the Propspective Payment System and the Treatment of Cardiac Disease.

Kletke, P. R. (1998). Trends in Physician Practice Arrangements. Socioeconomic Characteristics of Medical Practices 1997-98. Chicago, American Medical Association.

Kletke, P. R., D. W. Emmons, et al. (1996). "Current Trends in Physician Practice Arrangments." Journal of the American Medical Association 276(7): 555-560.

Kuo, Y.-F. and M. James S. Goodwin (2011). "Association of Hospitalist Care With Medical Utilization After Discharge: Evidence of Cost Shift From a Cohort Study." Annals of Internal Medicine(155): 152-159.

Landers, R. M., J. B. Rebitzer, et al. (1996a). "HUMAN RESOURCES PRACTICES AND THE DEMOGRAPHIC TRANSFORMATION OF PROFESSIONAL LABOR MARKETS 1996." BROKEN LADDERS: 215-245.

Landers, R. M., J. B. Rebitzer, et al. (1996b). "Rat Race Redux: Adverse Selection in the Determination of Work Hours in Law Firms." American Economic Review 86(3): 329-348.

Lang, K. and S. Majumdar (2004). "The Pricing of Job Characteristics When Markets Do Not Clear: Theory and Policy Implications." International Economic Review 45(4): 1111-1128.

Liebhaber, A. and J. M. Grossman (2007). Physicians Moving To Mid-Sized, Single-Specialty Practices. Tracking Report. Washington D.C., Center for Studying Health System Change.

Ludmerer, K. M. (1999). Time to heal: American medical education from the turn of the century to the era of managed care. New York, Oxford University Press.

McClellan, M. B. (2011). "Reforming Payments to Healthcare Providers: The Key to Slowing Healthcare Cost Growth While Improving Quality." Journal of Economic Perspectives 25(2): 69-92.

Meltzer, D. (2001). "Hospitalists and the Doctor Patient Relationships." Journal of Legal Studies 30.

Meltzer, D. O. and J. W. Chung (2010a). "Coordination, Switching Costs and the Division of Labor in General Medicine: An Economic Explanation for the Emergence of Hospitalists in the United States." National Bureau of Economic Research Working Paper Series No. 16040.

Meltzer, D. O. and J. W. Chung (2010b). "U.S. Trends in Hospitalization and Generalist Physician Workforce and the Emergence of Hospitalists." Journal General Internal Medicine 25(5): 453459.

National Center for Health Statistics (2011). Health United States 2010: With Special Feature on Dealth and Dying. Washington DC, Centers for Disease Control and Prevention.

Nyweide, D. J., W. B. Weeks, et al. (2009). "Relationship of Primary Care Physicians' Patient Caseload With Measurement of Quality and Cost Performance." JAMA: The Journal of the American Medical Association 302(22): 2444-2450. 
Ohsfeldt, R. L. (1983). Changing Medical Practice Arrangements Socioeconomic Monitoring Report. Chicago, American Medical Association. 2.

Pham, H. H., D. Schrag, et al. (2007). "Care Patterns in Medicare and Their Implications for Pay for Performance." New England Journal of Medicine 356(11): 1130-1139.

President's Council of Economic Advisors (2004). Economic Report of the President. Washington, D.C., United States Government Printing Office.

Rebitzer, J. B. and L. J. Taylor (2010). Extrinsic Rewards and Intrinsic Motives: Standard and Behavioral Approaches to Agency and Labor Markets. Handbook of Labor Economics. O. Ashenfelter and D. Card, North-Holland. 4A: 701-772.

Roberts, J. (2004). The Modern Firm: Organizational Design for Performance and Growth. Oxford, Oxford University Press.

Robinson, J. C. (1999). The corporate practice of medicine : competition and innovation in health care Berkeley, Calif. , University of California Press.

Rosenthal, M. (2008). "Beyond Pay for Performance - Emeging Models of Provider Payment Reform." New England Journal of Medicine 359(12): 4.

Ryan, A. M. and T. Doran (2012). "The effect of improving processes of care on patient outcomes: evidence from the United Kingdom's quality and outcomes framework." Medical Care 50(3): 191-199.

Shields, M. C., P. H. Patel, et al. (2011). "A Model For Integrating Independent Physicians Into Accountable Care Organizations." Health Affairs 30(1): 161-161-172.

Shortell, S. M., L. P. Casalino, et al. (2010). "How The Center For Medicare And Medicaid Innovation Should Test Accountable Care Organizations." Health Affairs 29(7): 1293-1293-1298.

Shortell, S. M., T. M. Waters, et al. (1998). "Physicians as Double Agents: Maintaining Trust in an Era of Multiple Accountabilities." Journal of the American Medical Association 280(12): 1102-1108.

Singer, S. and S. M. Shortell (2011). "Implementing Accountable Care Organizations." JAMA: The Journal of the American Medical Association.

Staiger, D. O., D. I. Aurebach, et al. (2010). "Trends in the Work Hours of Physicians in the United States." Journal of the American Medical Association 303(8): 6.

Starfield, B., L. Shi, et al. (2005). "Contributin of Primary Care to Health Systems and Health." Milbank Quarterly 83(3): 457-502.

Starr, P. (1984). The Social Transformation of American Medicine, Basic Books.

Stephen M. Campbell, P. D., P. D. David Reeves, et al. (2009). "Effects of Pay for Performance on the Quality of Primary Care in England." New England Journal of Medicine 361: 368-378.

Tim Doran, M. D., P. D. Evangelos Kontopantelis, et al. (2011). "Effect of financial incentives on incentivised and non-incentivised clinical activities: longitudinal analysis of data from the UK Quality and Outcomes Framework." British Medical Journal.

Wachter, R. M. (2004). Hospitalists in the United States: Mission Accomplished or Work in Progress? New England Journal of Medicine: 1935-1936.

Zenios, S., K. Surman, et al. (2004). Process Improvement in Stanford Hospital's Operation Room, Stanford Graduate School of Business. Case: OIT-41.

Zirui Song, D. G. Safran, et al. (2011). "Health Care Spending and Quality in Year 1 of the Alternative Quality Contract." New England Journal of Medicine. 